\title{
Ultrasound in management of rheumatoid arthritis: ARCTIC randomised controlled strategy trial
}

\begin{abstract}
Espen A Haavardsholm, ${ }^{1}$ Anna-Birgitte Aga, ${ }^{1}$ Inge Christoffer Olsen, ${ }^{1}$ Siri Lillegraven, ${ }^{1}$ Hilde B Hammer, Till Uhlig,, ${ }^{1}$ Hallvard Fremstad, ${ }^{2}$ Tor Magne Madland, ${ }^{3}$ Åse Stavland Lexberg, ${ }^{4}$ Hilde Haukeland, ${ }^{5}$ Erik Rødevand, ${ }^{6}$ Christian Høili, ${ }^{7}$ Hilde Stray, ${ }^{8}$ Anne Noraas, ${ }^{9}$ Inger Johanne Widding Hansen, ${ }^{10}$ Gunnstein Bakland, ${ }^{11,12}$ Lena Bugge Nordberg, ${ }^{1}$ Désirée van der Heijde, ${ }^{1,13}$ Tore K Kvien ${ }^{1}$
\end{abstract}

For numbered affiliations see end of article.

Correspondence to:

E A Haavardsholm

e.a.haavardsholm@medisin.uio.no Additional material is published online only. To view please visit the journal online.

Cite this as: BMJ 2016;354:i4205 http://dx.doi.org/10.1136/bmj.i4205

Accepted: 15 July 2016

\section{ABSTRACT}

OBJECTIVE

To determine whether a treatment strategy based on structured ultrasound assessment would lead to improved outcomes in rheumatoid arthritis, compared with a conventional strategy.

\section{DESIGN}

Multicentre, open label, two arm, parallel group, randomised controlled strategy trial.

\section{SETTING}

Ten rheumatology departments and one specialist centre in Norway, from September 2010 to September 2015.

PARTICIPANTS

238 patients were recruited between September 2010 and April 2013, of which 230 (141 (61\%) female) received the allocated intervention and were analysed for the primary outcome. The main inclusion criteria were age 18-75 years, fulfilment of the 2010 American College of Rheumatology/European League Against Rheumatism classification criteria for rheumatoid arthritis, disease modifying anti-rheumatic drug naivety with indication for disease modifying drug therapy, and time from first patient reported swollen joint less than two years. Patients with abnormal kidney or liver function or major comorbidities were excluded.

INTERVENTIONS

122 patients were randomised to an ultrasound tight control strategy targeting clinical and imaging remission, and 116 patients were randomised to a conventional tight control strategy targeting clinical remission. Patients in both arms were treated according to the same disease modifying anti-rheumatic drug escalation strategy, with 13 visits over two years.

\section{MAIN OUTCOME MEASURES}

The primary endpoint was the proportion of patients with a combination between 16 and 24 months of clinical remission, no swollen joints, and nonprogression of radiographic joint damage. Secondary outcomes included measures of disease activity, radiographic progression, functioning, quality of life, and adverse events. All participants who attended at least one follow-up visit were included in the full analysis set.

\section{RESULTS}

$26(22 \%)$ of the 118 analysed patients in the ultrasound tight control arm and 21 (19\%) of the 112 analysed patients in the clinical tight control arm reached the primary endpoint (mean difference 3.3\%, 95\% confidence interval $-7.1 \%$ to $13.7 \%$ ). Secondary endpoints (disease activity, physical function, and joint damage) were similar between the two groups. Six (5\%) patients in the ultrasound tight control arm and seven (6\%) patients in the conventional arm had serious adverse events.

\section{CONCLUSIONS}

The systematic use of ultrasound in the follow-up of patients with early rheumatoid arthritis treated according to current recommendations is not justified on the basis of the ARCTIC results. The findings highlight the need for randomised trials assessing the clinical application of medical technology.

TRIAL REGISTRATION

Clinical trials NCT01205854.

\section{Introduction}

The rapid development of medical equipment to help physicians in their decision making has led to fundamental changes in management of patients throughout medical specialties. The implementation of new techniques in clinical practice is often based on the opportunity to assess pathological findings thought to be of importance, but randomised clinical trials assessing the added value of new techniques on patients' outcomes are often not undertaken before care of patients is changed.

The management of rheumatoid arthritis has improved greatly over the past decade with the introduction of biologic agents, tight control strategies, and early disease modifying anti-rheumatic drug treatment. ${ }^{1-9}$ With the improvement in rheumatoid arthritis care, remission has become an achievable goal for a large proportion of patients, ${ }^{10-13}$ but studies have shown 
that clinical remission does not necessarily exclude progression of joint damage. ${ }^{1415}$ An increasing number of rheumatologists use ultrasound in the management of rheumatic diseases. Ultrasound can assess two aspects of synovitis-the morphology and quantity by grey scale and synovial vascularity by power Dopplerand it has been a promising tool for monitoring of disease activity in rheumatoid arthritis. ${ }^{16-18}$ Ultrasound has been shown to be more sensitive than clinical examination in detecting joint inflammation and to improve the certainty of a diagnosis of rheumatoid arthritis, ${ }^{19-22}$ and it may also be helpful in procedures such as aspiration of joint fluid and intra-articular corticosteroid injections. ${ }^{2324}$ Joint inflammation visualised by ultrasound is present in a majority of rheumatoid arthritis patients in clinical remission, and several studies have shown that power Doppler activity is associated with radiographic progression and disease flare in these patients. ${ }^{1925-30}$ The potential importance of ultrasound in the definition of rheumatoid arthritis remission and the monitoring of disease activity has led to interest in the concept of imaging remission-that is, abrogation of inflammation assessed by sensitive imaging techniques. ${ }^{31-35}$

The ARCTIC (Aiming for Remission in rheumatoid arthritis: a randomised trial examining the benefit of ultrasound in a Clinical TIght Control regimen) study was designed to compare two tight control treatment strategies for early rheumatoid arthritis to assess whether incorporation of ultrasound information into treatment decisions as well as targeting therapy towards imaging remission would lead to improvement in a combined outcome of sustained clinical remission, absence of swollen joints, and inhibition of joint damage.

\section{Methods}

Study design

The ARCTIC trial was a 24 month randomised, open label, parallel group clinical strategy study conducted at 11 centres in Norway (four rheumatology departments at university hospitals, six regional/community hospitals, and one private practice) in compliance with the Declaration of Helsinki and the International Conference on Harmonization Guidelines for Good Clinical Practice. The study was conducted and analysed according to the protocol and the statistical analysis plan (see appendix).

\section{Participants}

The main inclusion criteria were age 18-75 years, fulfilment of the 2010 American College of Rheumatology (ACR)/European League Against Rheumatism (EULAR) classification criteria for rheumatoid arthritis, ${ }^{36}$ naivety to disease modifying anti-rheumatic drugs, time from first patient reported swollen joint less than two years, and indication for disease modifying drug treatment. Patients with abnormal kidney or liver function or major comorbidities were excluded (full inclusion and exclusion criteria in section 2 of the appendix). All patients provided written informed consent.

\section{Randomisation and masking}

Patients were randomised one to one to either an "ultrasound tight control" or a "conventional tight control" strategy. The site investigators enrolled patients, and randomisation was computer generated with block design, concealment of allocation by opaque sequentially numbered sealed envelopes (prepared by a contract research organisation, Smerud Medical Research, Oslo, Norway), and stratification for study centre and presence of anti-cyclic citrullinated peptide antibodies. Investigators and patients were aware of the allocated treatment group. The readers of the radiographs were masked for clinical information and strategy arm, and unblinded study personnel made clinical assessments including joint counts.

\section{Assessments}

Patients were assessed at 0, 1, 2, 3, 4, 6, 8, 10, 12, 14, 16, 20, and 24 months. Patients in the ultrasound strategy arm were assessed by ultrasound at every visit, according to a scoring system of 32 joints with high intra-rater and inter-rater reliability. ${ }^{37}$ According to the scoring system, these 32 joints were scored semi-quantitatively as 0-3 for both grey scale and power Doppler: metacarpophalangeal joints 1-5, radiocarpal joint, intercarpal joint, distal radioulnar joint, elbow, knee, talocrural joint, and metatarsophalangeal joints 1-5 bilaterally, giving ranges from 0 to 192 for total ultrasound score and from 0 to 96 for grey scale and power Doppler ultrasound scores. The ultrasound assessments were performed with Siemens Antares or GE Logiq E9 ultrasound machines with linear probes (11.4/13.0 MHz). Power Doppler parameters were adjusted according to the device used (pulse repetition frequency $391 / 600 \mathrm{~Hz}$; Doppler frequency 7.3/10.0 MHz). ${ }^{38}$ No changes in ultrasound settings were made during the study, and no software was upgraded. Patients in the conventional tight control arm were assessed by ultrasound yearly, but both the patient and the treating physician were blinded to the results, and the treating physicians did not have access privileges to ultrasound data in the electronic case report form. In the ultrasound strategy arm, the sonographer was also the treating physician, and patients were informed of the ultrasound results. All the sonographers participating in the study were experienced and underwent extensive training with both static and dynamic hands-on exercises to calibrate readers before the inclusion of the first patient and an ultrasound workshop to ensure that calibration was repeated annually during data collection. A published atlas with ultrasound images showing the range of scores of both power Doppler and grey scale synovitis in the assessed joints was available at all study centres for reference. ${ }^{37}$ Multicentre training and calibration exercises of clinical joint examinations took place before the start of the study and at annual investigator meetings during the conduct of the study. Examinations were performed according to the EULAR handbook of clinical assessments in rheumatoid arthritis. ${ }^{39}$ 


\section{Treatment strategies}

The ultrasound tight control strategy targeted ultrasound imaging remission, defined as no ultrasound power Doppler signal in any assessed joint, in combination with clinical remission, whereas the clinical tight control strategy was targeted towards clinical remission only. We based the choice of no ultrasound power Doppler signal in any assessed joint as the preferred ultrasound treatment target on available literature and extensive discussions with clinicians and researchers. ${ }^{29}$ Clinical remission was defined as Disease Activity Score (DAS) below 1.6 and no swollen joints. DAS (range 0-10, higher score indicating more disease activity) is a composite index of four variables: the number of swollen joints among 44 examined joints, the Ritchie Articular Index with a graded assessment 0-3 of the tenderness in 26 joint regions, the erythrocyte sedimentation rate, and the patient's global assessment on a visual analogue scale ranging from 0 to $100 . .^{40}$ The treatment in both arms was escalated according to the same algorithm, shown in figure 1 (more details in section 3 of the appendix). The initial treatment was methotrexate $15 \mathrm{mg} /$ week increased to $20 \mathrm{mg} /$ week by week five, in combination with seven weeks of prednisolone with tapering doses from $15 \mathrm{mg}$ to zero. Further steps in the treatment algorithm included methotrexate $25 \mathrm{mg} /$ week, triple

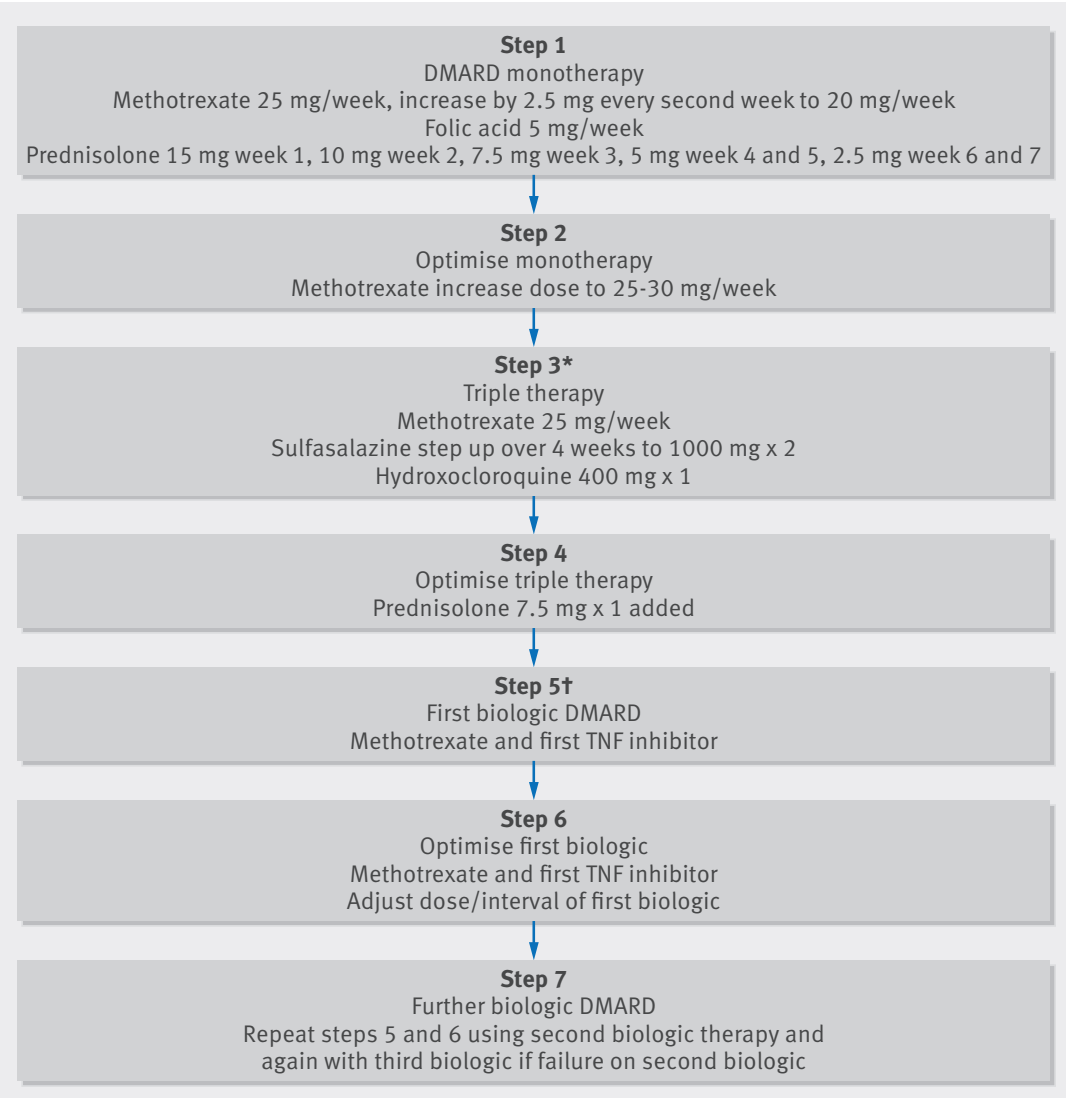

Fig 1 | Protocol for escalation of disease modifying anti-rheumatic (DMARD) treatment. If patient responds or reaches target, current treatment is continued. *In patients with high disease activity and risk factors for progressive joint destruction, rescue option is available which includes moving to step 5 (introduce first biologic). tThis step requires signs of ongoing inflammatory activity. TNF=tumour necrosis factor synthetic disease modifying drug therapy (methotrexate, sulfasalazine, hydroxychloroquine) and biologic treatment according to guidelines (fig 1 and appendix table S1). In both arms, swollen joints were treated by intra-articular steroids; additionally, any joint with power Doppler signal in the ultrasound tight control arm should be injected. All injections in the ultrasound tight control arm were guided by ultrasound.

The clinical decision to adjust therapy was based on level of and change in DAS. ${ }^{41}$ In the ultrasound arm, the physician should overrule the DAS based decision and proceed to the next treatment regimen if indicated by the ultrasound score. We applied a data driven approach to derive cut-off values for the ultrasound change score in a previously collected dataset using the same ultrasound score, by assessing the magnitude of changes in ultrasound score corresponding to established cut-off values for changes in DAS. The chosen cut-off values of $10 \%$ and $20 \%$ change in ultrasound scores corresponded to DAS changes of more than 0.6 and 1.2, respectively. If the patient did not respond adequately (appendix table S2), the physician immediately adjusted the therapy by proceeding to the next step in the treatment algorithm. Current therapy was continued if the treatment response was satisfactory. Study personnel entered information on DAS values at the current and previous visit, as well as the ultrasound score at both visits if applicable, into a web page that automatically applied the treatment decisions rules in the appropriate study arm (appendix table S2), and the treating physician was presented with the outcome of the response assessment and whether to escalate treatment.

\section{Outcomes}

The predefined primary efficacy endpoint was the proportion of patients meeting the following criteria: sustained clinical remission, defined as DAS less than 1.6 at 16, 20, and 24 months; no swollen joints at 16, 20, and 24 months; and no radiographic progression $(<0.5$ units change in van der Heijde modified Sharp score) between 16 and 24 months.

Radiographs of hands, wrists, and feet were obtained at $0,3,6,12,16$, and 24 months. Two trained readers, blinded for clinical data and treatment strategy, scored radiographs independently in chronological order according to the van der Heijde modified Sharp score (subscores for erosions (0-280) and joint space narrowing (0-168), total range 0-448, higher scores indicating more joint damage). We used the average of the two readings for all analyses.

Secondary endpoints included DAS remission, Simplified Disease Activity Index remission (this index ranges from 0 to 86 , with higher scores indicating more disease activity; remission is defined as an index $\leq 3.3$ ), ACR core set outcome variables (assessment of tender and swollen joints, pain, patient and investigator global assessment of disease activity, erythrocyte sedimentation rate, and $\mathrm{C}$ reactive protein), and fatigue visual analogue scale. We assessed physical function by the Patient-Reported Outcomes Measurement Information 20 item short form (range 20-100, translated to a 
T score with a mean of 50 and a standard deviation of 10). EuroQol-5 dimensions was assessed with values based on UK preference weights with range from 1 (best possible health), through 0 (death) to -0.59 (worse than death). We included the Rheumatoid Arthritis Impact of Disease score, a patient derived weighted score to assess seven domains of the impact of rheumatoid arthritis (range 0-10, where higher values indicate worse status). Additionally, we assessed changes from baseline in DAS and van der Heijde modified Sharp score, the proportion of patients with radiographic progression according to different cut-off values, and EULAR response rates (details in statistical analysis plan in appendix). A complete list of secondary outcomes is provided in the appendix. We have not reported a subset of the pre-specified outcomes, either because of feasibility problems or because the methodology and interpretation of results would be beyond the scope of this paper (magnetic resonance imaging outcomes, work productivity and activity impairment outcomes, dual energy $x$ ray absorptiometry outcomes, and outcomes from the Medical Outcomes Study Short Form 36 item). The results of these analyses will be published in full in more specialised journals and provided in the ClinicalTrials.gov database (NCT01205854). We evaluated safety by assessment of clinical and laboratory adverse events and coded serious adverse events according to the Medical Dictionary for Regulatory Activities (MedDRA, v17.0).

\section{Patient involvement}

No patients were involved in the development of the research question or the outcome measures, nor were

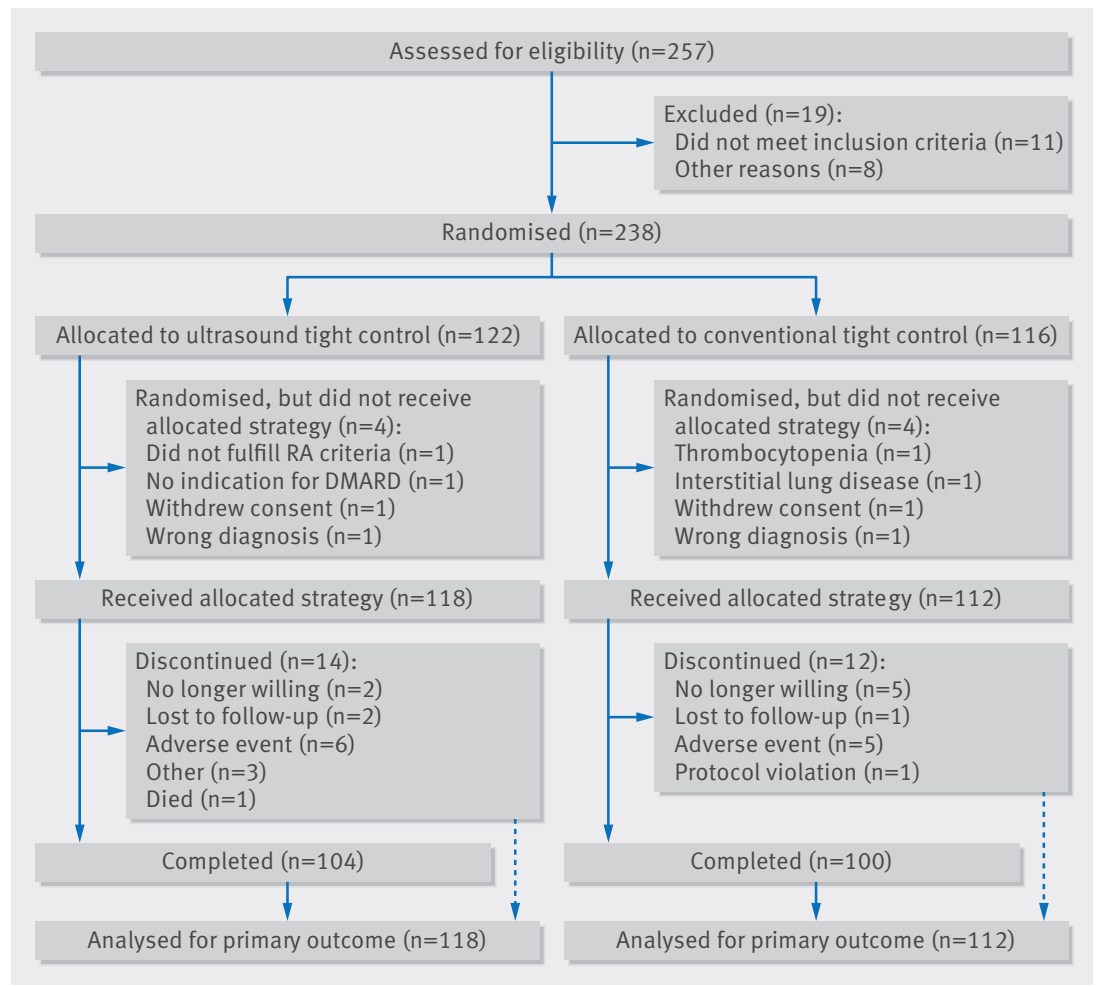

Fig 2 | Trial profile. DMARD=disease modifying anti-rheumatic drug; RA=rheumatoid arthritis they involved in the design of the study, the recruitment of study participants and the conduct of the study. The main results from the study will be disseminated to study participants in a study newsletter.

\section{Statistical analyses}

We determined the sample size on the basis of an assumed treatment difference of 20\% (45\% v 65\%) in the proportion of patients reaching the primary endpoint, yielding 98 patients in each group to reach $80 \%$ power. We aimed to include 240 patients to compensate for attrition. Efficacy and safety analyses included data from all randomised patients who started the allocated intervention by attending at least one regular visit after randomisation (the full analyses set).

We used unadjusted logistic regression to assess the primary endpoint and other categorical endpoints. We did not adjust the analyses for the stratification factors centre and presence of anti-cyclic citrullinated peptide antibodies owing to low cell frequencies. If the primary endpoint components or other categorical values were missing at month 24, we imputed values with worst outcome. We imputed missing values before month 24 with the last known value. We calculated estimates of risk difference from the logistic regression parameters by using the delta method to provide confidence intervals. We used median regression with 10000 bootstrap replications to estimate the difference in median radiographic change scores; we used linear intrapolation and extrapolation to impute missing values. To analyse other continuous change variables, we used analysis of covariance adjusted for baseline value in addition to study centre and presence of anti-cyclic citrullinated peptide antibodies. We used least square means to calculate estimates of treatment difference. We handled missing values by using multiple imputations with 10 imputations drawn from the observed distribution, using the Markov chain Monte Carlo method. The statistical significance level was set at 0.05, and all significance tests were two sided. Secondary analyses were not adjusted for multiple testing. Further statistical details are described in the statistical analyses plan and appendix section 4. A data monitoring committee was not established for this trial. We used Stata Statistical Software version 14 for all statistical analyses.

\section{Results}

Patient disposition and baseline characteristics

Between 30 September 2010 and 30 April 2013, 238 patients with early rheumatoid arthritis were included in the ARCTIC trial (fig 2). One hundred and eighteen patients received the allocated ultrasound tight control treatment strategy and 112 patients received the conventional tight control strategy and were included in the primary analysis (fig 2). Of the included patients, 104 completed the ultrasound tight control arm and 100 completed the conventional tight control arm. The frequencies and reasons for not receiving allocated treatment strategy and for discontinuation during the study were similar in the two arms. The two arms were well balanced overall with regard to baseline characteristics, but more women 


\begin{tabular}{|c|c|c|}
\hline Characteristics & $\begin{array}{l}\text { Ultrasound tight } \\
\text { control }(n=118)\end{array}$ & $\begin{array}{l}\text { Conventional tight } \\
\text { control }(n=112)\end{array}$ \\
\hline Age, years & $50.6(13.3)$ & $52.3(14.1)$ \\
\hline No (\%) women & $84(71)$ & $57(51)$ \\
\hline Body mass index & $25.6(4.4)$ & $26.1(4.7)$ \\
\hline No (\%) current smoker & $23(19)$ & $32(29)$ \\
\hline Time since patient reported first swollen joint, months & $6.8(5.2)$ & $7.4(5.6)$ \\
\hline No (\%) anti-citrullinated peptide antibody positive & $93(79)$ & $93(83)$ \\
\hline No (\%) rheumatoid factor positive & $78(66)$ & $86(77)$ \\
\hline Disease Activity Score & $3.51(1.19)$ & $3.40(1.16)$ \\
\hline Simplified Disease Activity Index & $25.5(12.9)$ & $24.4(13.3)$ \\
\hline Disease Activity Score based on 28 joints & $4.42(1.19)$ & $4.39(1.20)$ \\
\hline Patient's global assessment of disease activity, mm (0-100) & $51.9(24.7)$ & $47.5(23.9)$ \\
\hline Investigator's global assessment of disease activity, mm (0-100) & $40.9(20.1)$ & $40.3(21.2)$ \\
\hline Swollen joint count $(0-44)$ & $10.9(7.2)$ & $10.2(7.8)$ \\
\hline Tender joint count (Ritchie Articular Index, 0-78) & $9.2(7.9)$ & $8.4(6.7)$ \\
\hline Erythrocyte sedimentation rate, mm/hr (1-140) & $23.2(18.3)$ & $25.8(18.9)$ \\
\hline C reactive protein, $\mathrm{mg} / \mathrm{L}$ & $14.5(20.1)$ & $16.6(22.39$ \\
\hline PROMIS Physical Function (12.1-62.5) & $38.9(9.2)$ & $39.2(8.1)$ \\
\hline Median (IQR) EuroQol-5 dimensions (-0.59-1.0) & $0.66(0.16-0.73)$ & $0.66(0.47-0.73)$ \\
\hline Fatigue visual analogue scale, mm (0-100) & $43.7(28.4)$ & $37.0(28.6)$ \\
\hline Pain visual analogue scale, mm (0-100) & $48.8(23.9)$ & $46.8(24.3)$ \\
\hline Median (IQR) van der Heijde modified Sharp score (0-448) & $3.8(1.5-7.5)$ & $5.0(2.0-10.3)$ \\
\hline Median (IQR) erosion score & $2.5(1.0-4.0)$ & $3.5(1.5-5.8)$ \\
\hline Median (IQR) joint space narrowing score & $1.0(0.0-3.0)$ & $1.0(0.0-4.5)$ \\
\hline Median (IQR) ultrasound total score (0-192) & $24(16-37)$ & $27(14-45)$ \\
\hline Median (IQR) ultrasound grey scale score & $17(10-24)$ & $19(10-31)$ \\
\hline Median (IQR) ultrasound power Doppler & $7(3-13)$ & $7(2-15)$ \\
\hline No (\%) power Doppler signal in any joint & $110(93.2)$ & $97(86.6)$ \\
\hline
\end{tabular}

were randomised to the ultrasound arm (71\% v 51\%) (table 1). The difference in sex distribution could not be attributed to a specific study centre (appendix table S5).

\section{Clinical outcomes}

The ultrasound tight control strategy was not superior to the conventional tight control strategy with regards to the primary outcome (sustained remission, absence of radiographic damage, and absence of swollen joints between month 16 and 24 of the study). Twenty six (22\%) patients in the ultrasound tight control group and $21(19 \%)$ patients in the conventional tight control group reached the primary outcome, with a difference between the groups of 3.3\% (95\% confidence interval -7.1 to $13.7 ; \mathrm{P}=0.54)$ and a risk ratio of 1.18 (95\% confidence interval 0.57 to 1.78 ). We found no difference between the groups for any of the three components of the primary outcome (table 2).

At 24 months, $68 \%$ and $67 \%$ of the patients in the two arms were in DAS remission (table 2). We found no significant differences in remission rates at 12 or 24 months for either of the remission criteria sets analysed. DAS scores, DAS remission rates, Simplified Disease Activity Index remission rates, and ACR/EULAR boolean remission rates were comparable in the two study arms during the 24 month study period (fig 3). More than $80 \%$ of patients in both arms showed EULAR good or moderate response at 12 months, and this was sustained throughout the study. The patients' and assessors' evaluation of the disease activity showed substantial improvement compared with baseline, with similar results at 12 and 24 months. Patients in both groups reported similar levels of improvement in physical function. More patients in the ultrasound tight control arm (29\%) than in the conventional tight control arm $(17 \%)$ received biologic treatment at the end of the study, and fewer patients received methotrexate monotherapy (53\% v 71\%). In the ultrasound tight control arm, 167 treatment escalations and 770 intra-articular corticosteroid injections occurred, compared with 124 treatment escalations and 548 intra-articular corticosteroid injections in the conventional tight control arm.

\section{Radiographic outcomes}

The median change in total van der Heijde modified Sharp score over 24 months was low, with no statistically significant differences between the two strategies. We observed a borderline statistically significant difference in the 24 month change in radiographic joint damage between the groups, favouring the ultrasound tight control strategy (table 2), and this is visualised in the cumulative probability plot (fig 4). The proportion of patients with radiographic progression did not differ between the two strategy arms (table 2), and we found similar results in sensitivity analyses with different cut-off values for yearly progression ( $\geq 0.5$ units, $\geq 2.0$ units, $\geq 5$ units).

\section{Sensitivity analyses}

In sensitivity analyses, we analysed the primary endpoint, components of the primary endpoint, and the 


\section{Table 2 | Primary and secondary outcomes. Values are numbers (percentages) unless stated otherwise}

\begin{tabular}{|c|c|c|c|c|}
\hline & $\begin{array}{l}\text { Ultrasound tight } \\
\text { control }(n=118)\end{array}$ & $\begin{array}{l}\text { Conventional tight } \\
\text { control }(n=112)\end{array}$ & Difference $(95 \% \mathrm{Cl})$ & P value \\
\hline \multicolumn{5}{|l|}{ Primary endpoint } \\
\hline Clinical remission, no swollen joints, and non-progression of radiographic joint damage & $26(22)$ & $21(19)$ & $3.3(-7.1$ to 13.7$)$ & 0.54 \\
\hline \multicolumn{5}{|l|}{ Components of primary endpoint } \\
\hline No swollen joints at 16,20 , and 24 months $^{\star}$ & $62(53)$ & $61(54)$ & $-1.9(-14.8$ to 11.0$)$ & 0.77 \\
\hline Disease Activity Score remission at 16, 20, and 24 months $^{\star}$ & $64(54)$ & $58(52)$ & $2.5(-10.4$ to 15.4$)$ & 0.71 \\
\hline No radiographic progression between 16 and 24 months $^{\star}$ & $49(42)$ & $39(35)$ & $6.7(-5.8$ to 19.2$)$ & 0.29 \\
\hline \multicolumn{5}{|l|}{ Measures of disease activity, physical function, and quality of life } \\
\hline \multicolumn{5}{|l|}{ Mean (SD) change in Disease Activity Score: } \\
\hline At 12 months & $-2.2(1.1)$ & $-2.1(1.2)$ & $0.1(-0.1$ to 0.3$)$ & 0.26 \\
\hline At 24 months & $-2.3(1.2)$ & $-2.0(1.2)$ & $-0.1(-0.3$ to 0.1$)$ & 0.49 \\
\hline \multicolumn{5}{|l|}{ Disease Activity Score remission (Disease Activity Score <1.6)t: } \\
\hline At 12 months & $76(64)$ & $81(72)$ & $-7.9(-19.9$ to 4.1$)$ & 0.20 \\
\hline At 24 months & $80(68)$ & $75(67)$ & $0.8(-11.3$ to 13.0$)$ & 0.89 \\
\hline \multicolumn{5}{|l|}{ Mean (SD) change in erythrocyte sedimentation rate, $\mathrm{mm} / \mathrm{hr}$ : } \\
\hline At 12 months $\ddagger$ & $-11.6(16.5)$ & $-14.9(18.6)$ & $0.9(-1.2$ to 3.1$)$ & 0.39 \\
\hline At 24 months $\ddagger$ & $-13.0(16.8)$ & $-13.7(17.7)$ & $-1.1(-3.3$ to 1.0$)$ & 0.30 \\
\hline \multicolumn{5}{|l|}{ Mean (SD) change in C reactive protein, $\mathrm{mg} / \mathrm{L}$ : } \\
\hline At 12 months $¥$ & $-10.1(19.6)$ & $-11.7(21.6)$ & $0(-1.1$ to 1.0$)$ & 0.92 \\
\hline At 24 months $\ddagger$ & $-11.0(19.9)$ & $-11.3(21.9)$ & $-1.0(-2.3$ to 0.2$)$ & 0.11 \\
\hline \multicolumn{5}{|l|}{ Mean (SD) change in investigator's global assessment: } \\
\hline At 12 months $¥$ & $-34.8(19.9)$ & $-29.9(21.2)$ & $-1.3(-3.3$ to 0.7$)$ & 0.19 \\
\hline At 24 months $\ddagger$ & $-33.0(21.6)$ & $-28.0(23.2)$ & $-2.6(-5.5$ to 0.4$)$ & 0.09 \\
\hline \multicolumn{5}{|l|}{ Mean (SD) change in patient's global assessment: } \\
\hline At 12 months $\ddagger$ & $-35.1(25.3)$ & $-29.2(28.8)$ & $-1.3(-6.3$ to 3.7$)$ & 0.61 \\
\hline At 24 months $\ddagger$ & $-35.9(25.9)$ & $-29.7(28.1)$ & $-0.75(-6.0$ to 4.5$)$ & 0.78 \\
\hline \multicolumn{5}{|l|}{ Mean (SD) change in Disease Activity Score 28 joints: } \\
\hline At 12 months $\ddagger$ & $-2.4(1.3)$ & $-2.4(1.4)$ & $0.1(-0.1$ to 0.4$)$ & 0.29 \\
\hline At 24 months $\ddagger$ & $-2.5(1.3)$ & $-2.2(1.3)$ & $-0.2(-0.4$ to 0.1$)$ & 0.23 \\
\hline \multicolumn{5}{|l|}{ Mean (SD) change in Simplified Disease Activity Index: } \\
\hline At 12 months $¥$ & $-21.3(12.6)$ & $-18.9(12.8)$ & $-0.1(-1.3$ to 1.0$)$ & 0.83 \\
\hline At 24 months $\ddagger$ & $-20.8(13.5)$ & $-18.3(13.1)$ & $-0.5(-2.1$ to 1.1$)$ & 0.56 \\
\hline \multicolumn{5}{|l|}{ Simplified Disease Activity Index remission (Simplified Disease Activity Index<3.3)t: } \\
\hline At 12 months & $67(57)$ & $61(54)$ & $2.3(-10.5$ to 15.2$)$ & 0.72 \\
\hline At 24 months & $71(60)$ & $56(50)$ & $10.2(-2.6$ to 23.0$)$ & 0.12 \\
\hline \multicolumn{5}{|l|}{ ACR-EULAR boolean remissiont: } \\
\hline At 12 months & $50(42)$ & $47(42)$ & $0.4(-12.4$ to 13.2$)$ & 0.95 \\
\hline At 24 months & $57(48)$ & $55(49)$ & $-0.8(-12.7$ to 12.1$)$ & 0.90 \\
\hline \multicolumn{5}{|l|}{ EULAR good/moderate responset: } \\
\hline At 12 months & $97(82)$ & $93(83)$ & $-0.8(-10.6$ to 9.0$)$ & 0.87 \\
\hline At 24 months & $98(83)$ & $90(80)$ & $2.7(-7.3$ to 12.7$)$ & 0.60 \\
\hline \multicolumn{5}{|l|}{ No tender jointst‡: } \\
\hline At 12 months & $57(48)$ & $64(57)$ & $-8.8(-21.7$ to 4.0$)$ & 0.18 \\
\hline At 24 months & $67(57)$ & $60(54)$ & $3.2(-9.6$ to 16.1$)$ & 0.63 \\
\hline \multicolumn{5}{|l|}{ No swollen joints†‡: } \\
\hline At 12 months & $87(74)$ & $78(70)$ & $4.1(-7.6$ to 15.7$)$ & 0.49 \\
\hline At 24 months & $84(71)$ & $75(67)$ & $4.2(-7.7$ to 16.2$)$ & 0.49 \\
\hline \multicolumn{5}{|l|}{ Mean (SD) change in PROMIS Physical Function: } \\
\hline At 12 months & $11.6(9.1)$ & $11.6(8.6)$ & $-0.3(-2.4$ to 1.8$)$ & 0.80 \\
\hline At 24 months & $13.0(9.5)$ & $11.0(9.6)$ & $1.28(-1.1$ to 3.6$)$ & 0.28 \\
\hline Mean (SD) change in EQ-5D: & & & & \\
\hline At 12 months $\ddagger$ & $0.28(0.28)$ & $0.25(0.29)$ & $0(-0.05$ to 0.05$)$ & 0.95 \\
\hline At 24 months & $0.30(0.28)$ & $0.26(0.28)$ & $-0.01(-0.06$ to 0.05$)$ & 0.84 \\
\hline Mean (SD) change in Rheumatoid Arthritis Impact of Disease score: & & & & \\
\hline At 12 months & $-2.6(2.0)$ & $-2.4(2.3)$ & $-0.08(-0.51$ to 0.35$)$ & 0.71 \\
\hline At 24 months & $-2.8(2.1)$ & $-2.5(2.3)$ & $-0.06(-0.49$ to 0.38$)$ & 0.79 \\
\hline Mean (SD) change in fatigue visual analogue scale: & & & & \\
\hline At 12 months $¥$ & $-20.0(31.4)$ & $-15.6(28.5)$ & $1.0(-4.9$ to 6.8$)$ & 0.75 \\
\hline At 24 months $\ddagger$ & $-20.8(32.7)$ & $-14.8(28.7)$ & $1.7(-4.8$ to 8.2$)$ & 0.61 \\
\hline
\end{tabular}




\begin{tabular}{|c|c|c|c|c|}
\hline & $\begin{array}{l}\text { Ultrasound tight } \\
\text { control }(n=118)\end{array}$ & $\begin{array}{l}\text { Conventional tight } \\
\text { control }(n=112)\end{array}$ & Difference $(95 \% \mathrm{Cl})$ & Pvalue \\
\hline \multicolumn{5}{|l|}{ Mean (SD) change in pain visual analogue scale: } \\
\hline At 12 months $\ddagger$ & $-32.5(24.8)$ & $-29.2(28.1)$ & $-0.82(-6.0$ to 4.3$)$ & 0.75 \\
\hline At 24 months $\ddagger$ & $-31.9(26.7)$ & $-29.1(25.0)$ & $0.03(-5.1$ to 5.2$)$ & 0.99 \\
\hline \multicolumn{5}{|l|}{ Radiographic joint damage } \\
\hline \multicolumn{5}{|l|}{ Median (IQR) changes in modified Sharp score: } \\
\hline At 12 months & $0.5(0-1.0)$ & $0.5(0-1.5)$ & $-0.28(-0.60$ to 0.04$)$ & 0.08 \\
\hline At 24 months & $1.0(0-2.5)$ & $1.5(0.5-3.0)$ & $-0.45(-0.90$ to 0$)$ & 0.05 \\
\hline \multicolumn{5}{|l|}{ Median (IQR) change in erosion score: } \\
\hline At 12 months & $0(0-1.0)$ & $0.5(0-1.0)$ & $-0.35(-0.70$ to 0$)$ & 0.05 \\
\hline At 24 months & $0.5(0-1.5)$ & $1.0(0.5-2.0)$ & $-0.38(-0.76$ to 0.01$)$ & 0.06 \\
\hline \multicolumn{5}{|l|}{ Median (IQR) change in joint space narrowing score: } \\
\hline At 12 months & $0(0-0.5)$ & $0(0-0)$ & $0(-0.03$ to 0.03$)$ & $>0.99$ \\
\hline At 24 months & $0(0-0.5)$ & $0(0.0-0.5)$ & $0(-0.05$ to 0.05$)$ & $>0.99$ \\
\hline Progression, modified Sharp score $\geq 1.0$ units/year & $43(36)$ & $53(47)$ & $-10.9(-23.6$ to 1.8$)$ & 0.09 \\
\hline \multicolumn{5}{|l|}{ Ultrasound outcomes } \\
\hline \multicolumn{5}{|l|}{ Mean (SD) change in ultrasound total score: } \\
\hline At 12 months & $-25.0(18.3)$ & $-23.7(23.4)$ & $-3.7(-5.8$ to -1.7$)$ & $<0.001$ \\
\hline At 24 months & $-25.5(18.3)$ & $-26.7(26.1)$ & $-2.2(-4.0$ to -0.42$)$ & 0.02 \\
\hline \multicolumn{5}{|l|}{ Mean (SD) change in ultrasound grey scale score: } \\
\hline At 12 months & $-15.9(11.6)$ & $-15.0(13.9)$ & $-2.7(-4.3$ to -1.2$)$ & 0.001 \\
\hline At 24 months & $-16.5(11.6)$ & $-17.1(15.6)$ & $-1.6(-2.9$ to -0.28$)$ & 0.02 \\
\hline \multicolumn{5}{|l|}{ Mean (SD) change in ultrasound power Doppler: } \\
\hline At 12 months & $-9.2(8.2)$ & $-8.8(10.5)$ & $-1.0(-1.7$ to -0.29$)$ & 0.007 \\
\hline At 24 months & $-9.0(8.1)$ & $-9.6(11.5)$ & $-0.61(-1.3$ to 0.04$)$ & 0.06 \\
\hline \multicolumn{5}{|l|}{ No power Doppler signal in any jointt: } \\
\hline At 12 months & $94(80)$ & $60(54)$ & 26.1 (14.3 to 37.8$)$ & $<0.001$ \\
\hline At 24 months & $89(75)$ & $69(62)$ & $13.8(1.9$ to 25.7$)$ & 0.02 \\
\hline \multicolumn{5}{|l|}{ Drug treatment $\neq$} \\
\hline \multicolumn{5}{|l|}{ Disease modifying anti-rheumatic drug regimen at 24 months: } \\
\hline Methotrexate monotherapy & $63(53)$ & $80(71)$ & $-18.0(-30.3$ to -5.8$)$ & 0.004 \\
\hline Methotrexate/sulfasalazine/hydroxychloroquine combination & $21(18)$ & $13(12)$ & $6.2(-2.9$ to 15.3$)$ & 0.18 \\
\hline Biologic treatment & $34(29)$ & $19(17)$ & $11.8(1.1$ to 22.6$)$ & 0.03 \\
\hline First biologic & $27(23)$ & $10(9)$ & $14.0(4.7$ to 23.2$)$ & 0.003 \\
\hline Second biologic & $5(4)$ & $9(8)$ & $-3.8(\mathrm{v} 10.0$ to 2.4$)$ & 0.23 \\
\hline Third biologic & $2(2)$ & $0(0)$ & NE & 0.50 \\
\hline Mean (SD) methotrexate dose at 24 months, mg & $20.4(5.0)$ & $21.1(4.5)$ & $-0.7(-2.1$ to 0.6$)$ & 0.28 \\
\hline Median (IQR) total prednisolone dose, $\mathrm{mg} \S$ & $570(420-890)$ & $634(468-844)$ & $-2.5(-71.5$ to 66.5$)$ & 0.94 \\
\hline Any NSAID use over 24 months & $55(47)$ & $52(46)$ & $0(-0.12$ to 0.13$)$ & 0.98 \\
\hline Any intra-articular injections & $103(87)$ & $86(77)$ & $10.5(0.6$ to 20.4$)$ & 0.04 \\
\hline Mean (SD) No of intra-articular injections & $6.5(6.0)$ & $4.9(5.9)$ & $1.7(0.2$ to 3.2$)$ & 0.03 \\
\hline Mean (SD) total triamcinolone hexacetonide dose, $\mathrm{mg} \S$ & $94(88)$ & $69(129)$ & $25(-4$ to 54$)$ & 0.09 \\
\hline \multicolumn{5}{|c|}{$\begin{array}{l}\text { ACR=American College of Rheumatology; EQ-5D=EuroQol-5 dimensions; EULAR=European League Against Rheumatism; NE=not estimable (Pvalue based on Fischer's exact test for third } \\
\text { biologic); NSAID=non-steroidal anti-inflammatory drug; PROMIS=Patient-reported Outcomes Measurement Information Score Short Form v1.0 - Physical Function } 20 \text { a (reported as T scores). } \\
\text { *Missing data before } 24 \text { months imputed using last observation carried forward; missing data at } 24 \text { months imputed using worst outcome. } \\
\text { tMissing data were imputed using worst outcome imputation. } \\
\text { fOutcomes not listed in the ClinicalTrials.gov registry on } 20 \text { September } 2010 \text { (before patient enrolment), but described in trial protocol and/or statistical analyses plan before database lock an } \\
\text { analyses (see appendix). } \\
\text { §Cumulative dose per patient. }\end{array}$} \\
\hline
\end{tabular}

24 month change in radiographic damage with adjustment for sex (appendix table S3), with similar results as for the main analysis. We also found similar results in analyses of the primary endpoint with imputation of best outcome instead of worst outcome (data not shown). We also analysed the same variables in the completer dataset consisting of 204 patients (appendix table S4). In these analyses, we found a significant difference in radiographic damage over 24 months, with a difference in change of van der Heijde Sharp score of 0.45 units ( $95 \%$ confidence interval -0.86 to -0.39 ; $\mathrm{P}=0.03$ ) favouring the ultrasound tight control group.

\section{Adverse events}

The overall frequency of adverse events and serious adverse events was similar in the two arms (table 3 ). Thirteen $(6 \%)$ patients had serious adverse events, of whom five (2\%) had serious infections (table 3, appendix table S6). Five cases of cancer were reported: two (follicle centre lymphoma, liver metastases) in the ultrasound tight control arm and three (basal cell carcinoma, breast cancer, squamous cell carcinoma) in the conventional tight control arm (appendix section 5). One patient in the ultrasound tight control arm died from Pneumocystis jirovecii pneumonia (appendix section 6). 

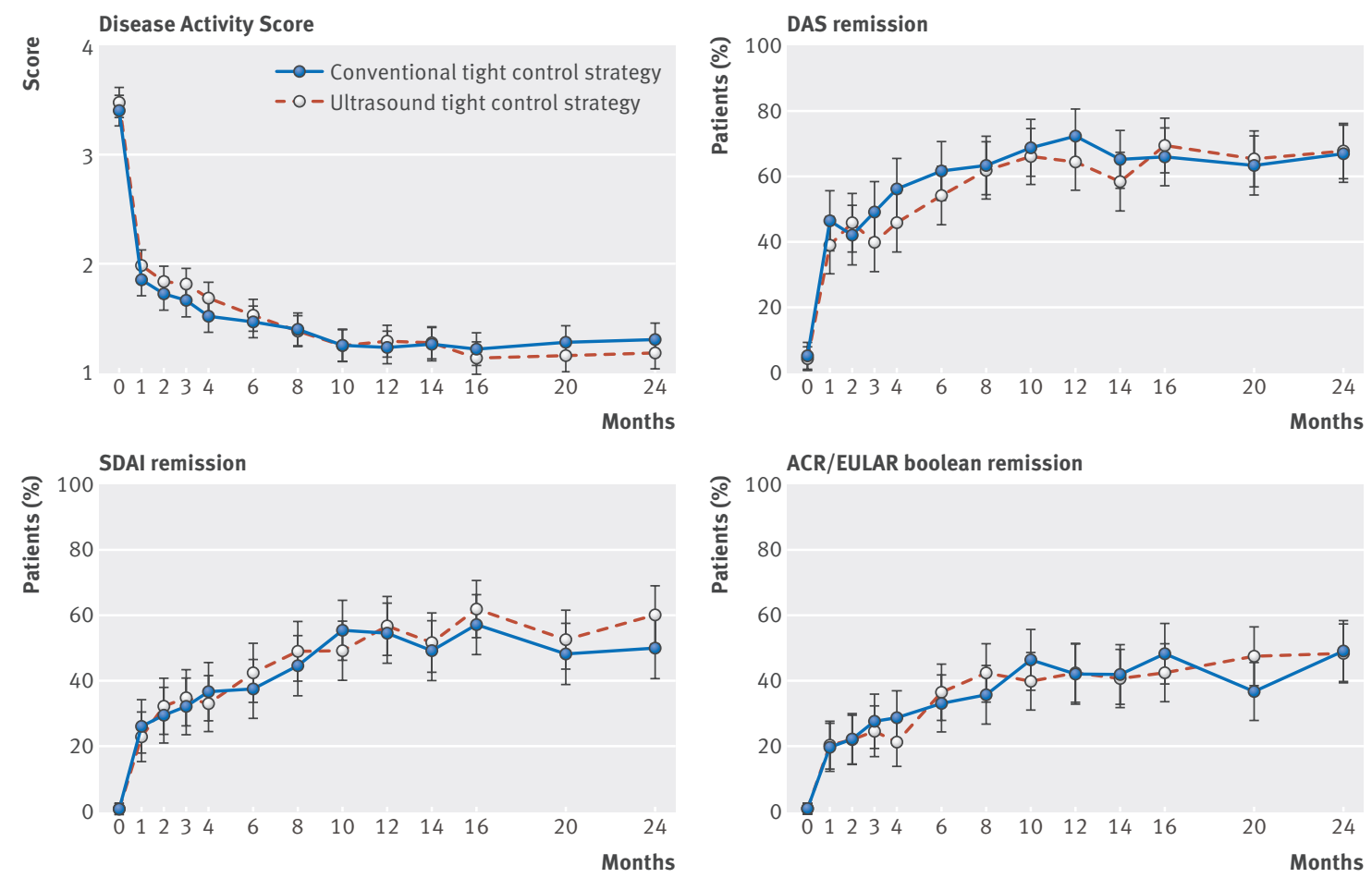

Fig 3 | Top left: Disease Activity Score (DAS) over 24 months; least square mean estimates of DAS at all visits derived from mixed effects longitudinal model adjusted for baseline value and stratification factors. Top right: proportion of patients who achieved DAS remission over 24 months derived from logistic regression model. Bottom left: proportion of patients who achieved Simplified Disease Activity Index (SDAI) remission over 24 months derived from logistic regression model. Bottom right: proportion of patients who achieved American College of Rheumatology (ACR)/European League Against Rheumatism (EULAR) boolean remission over 24 months from logistic regression model. Bars indicate $95 \%$ confidence limits

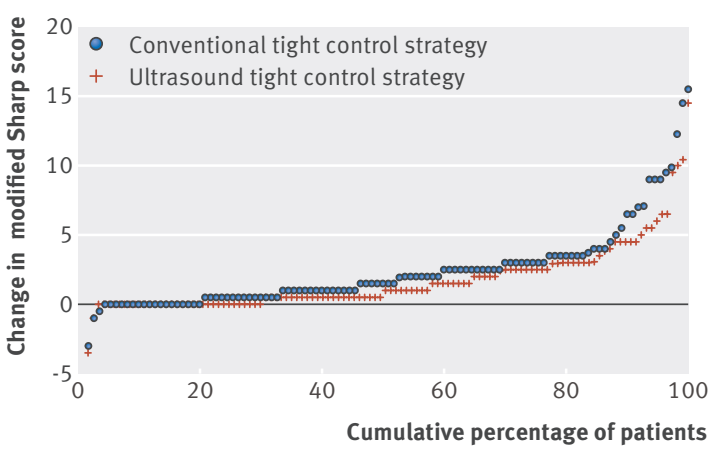

Fig 4 | Cumulative probability plot of change between baseline and 24 months in van der Heijde modified Sharp score

\section{Discussion}

In this study, we assessed the benefit of adding ultrasound information to the treatment decisions and treatment target in early rheumatoid arthritis. The study was designed on the basis of the increasing application of ultrasound in clinical practice, as well as several studies showing that ultrasound examinations improve assessment of synovitis and prediction of important patient outcomes. ${ }^{19}$ Our study found no additional effect of an ultrasound tight control strategy compared with a conventional tight control strategy for the primary outcome of the study or for other measures of disease activity, joint damage, and physical function.

\section{Strengths and limitations of study}

The study has limitations as well as strengths. This was an open study, and two components of the primary endpoint, the tender and swollen joint counts, were not blinded. This leaves a potential for bias in treatment decisions based on these parameters. Although remission rates were excellent, fewer patients than expected in the power calculations reached the strict composite primary outcome. In our sample size estimations, we aimed for $80 \%$ power to detect a $20 \%$ difference between the interventions (see protocol). If the study was to be repeated, the power to detect a $20 \%$ difference in the primary endpoint from $19 \%$ in the control group would have been $89 \%$, showing that the completed trial was not underpowered to detect a clinically important difference. This can also be deduced from the results presented in this manuscript. The estimated treatment difference of the primary endpoint was 3.3\% with a 95\% confidence interval of -7.1 to 13.7. The confidence limits of the primary efficacy outcome are completely within the $\pm 20 \%$ margin, excluding a clinically significant effect of the intervention (appendix section 7). Sensitivity analyses in the completer population and analyses in the full analyses set with imputation of best outcome instead of worst outcome resulted in similar results, supporting our conclusion. A pilot study showed good intra-reader and inter-reader reliability for the ultrasound scoring system, ${ }^{37}$ but no consensus has been reached on the optimal scoring system for ultra- 


\begin{tabular}{|c|c|c|}
\hline Outcome & $\begin{array}{l}\text { Ultrasound tight } \\
\text { control }(n=118)\end{array}$ & $\begin{array}{l}\text { Conventional } \\
\text { tightcontrol }(n=112)\end{array}$ \\
\hline Adverse events & 417 & 455 \\
\hline Patients with adverse events & $96(81)$ & $91(81)$ \\
\hline Patients with serious adverse events & $6(5)$ & $7(6)$ \\
\hline Patients with serious infection & $3(3)^{\star}$ & $2(2) \dagger$ \\
\hline Discontinuation from study due to adverse event & $7(6)$ & $5(4)$ \\
\hline Patients with cancer & $2(2) \ddagger$ & $3(3) \S$ \\
\hline Death & $1(1) \emptyset$ & 0 \\
\hline \multicolumn{3}{|c|}{$\begin{array}{l}\text { *Pneumocystis jirovecii pneumonia, pneumonia, and bacterial abscess. } \\
\text { †Abscess and localised infection. } \\
\text { †Follicle centre lymphoma and metastases to liver. } \\
\S \text { Basal cell carcinoma, breast cancer, and squamous cell carcinoma. } \\
\text { १Patient died from Pneumocystis jirovecii pneumonia. }\end{array}$} \\
\hline
\end{tabular}

sound in rheumatoid arthritis. ${ }^{18}$ Our findings are strengthened by both strategies adhering to international recommendations, ${ }^{1013}$ and by the fact that the primary endpoint comprised sustained clinical remission and halt of radiographic progression, thus capturing the most important aspects of rheumatoid arthritis. ${ }^{4}$ Two trained and blinded readers at a central facility read radiographs with known chronological order, to optimise sensitivity to change. ${ }^{42}$ The inclusion criteria stated that the patients should have a clinical indication for disease modifying anti-rheumatic drug therapy, as well as a diagnosis of rheumatoid arthritis and fulfilment of the 2010 ACR/EULAR classification criteria. We imposed no formal entry criteria regarding the level of DAS. At baseline, the mean DAS was in the upper range of moderate. We aimed to include a study population capturing a broad range of rheumatoid arthritis disease activity, not a subset with high disease activity, as is often the case in studies of new drugs. We believe this heterogeneity to be a strength of the study, as it reflects real life practice.

\section{Comparison with other studies}

The introduction of biologic therapies in combination with aggressive treatment strategies has led to levels of disease control previously thought impossible in rheumatoid arthritis, and remission has become a realistic goal of therapy. ${ }^{349-1315}$ Remission rates in both study arms of this trial were excellent compared with other trials of strategy in early rheumatoid arthritis, with minimal radiographic progression. ${ }^{14-46}$ Our results showcase the power of a treatment approach targeting deep clinical remission, follow-up with tight control, and starting treatment with methotrexate and prednisolone, combined with intra-articular injections in swollen joints. After 24 months, more than $70 \%$ of patients in the conventional arm were still on methotrexate monotherapy and only $17 \%$ needed a biologic agent. In an ideal setting, remission in rheumatoid arthritis should represent absence of inflammation and no progression of joint damage, but current clinical remission criteria do not include imaging assessments. A key question has been whether treatment of subclinical inflammation would improve long term outcomes or whether this will lead to overtreatment. ${ }^{19313235}$ We are aware of one other trial (NCT00920478) designed to assess the value of ultrasound in rheumatoid arthritis. The clinical target of that study was low disease activity and not remission, which is the preferred target in current treatment recommendations. ${ }^{113}$ Results from this trial indicate similar clinical and radiographic outcomes in both study arms. ${ }^{47}$

Possible explanations and implications for clinicians The outcome of the study is to a certain degree surprising, in that a growing body of evidence suggested that subclinical inflammation, especially power Doppler activity, was associated with radiographic progression and flares. ${ }^{192526282931}$ However, a recent study showed that radiographic progression was rare in joints with subclinical inflammation. ${ }^{48}$ The ultrasound strategy led to additional changes in disease modifying drug therapy, with fewer patients remaining on methotrexate monotherapy and more patients receiving biologic treatment, as well as a higher number of intra-articular corticosteroid injections. Adherence of patients and physicians to a pre-specified treatment protocol targeting remission can be challenging, and in several clinical situations rheumatologists may be reluctant to base treatment decisions solely on an algorithm rather than integrating all available information. A recent report from the BeST study evaluated rheumatologists' adherence to a treat to target strategy steered by DAS, and average protocol adherence was $79 \% .{ }^{49}$ In our trial, we found that $19 \%$ of treatment changes deviated from the decision rules of the treatment algorithm. The result of each ultrasound joint assessment in the ultrasound tight control arm was communicated to the patient, and despite the extra time and effort required, most patients appreciated the opportunity to directly observe the level of inflammation inside the joints. This may contribute to increased adherence of patients to therapy, in that ongoing inflammation would improve patients' motivation to escalate treatment and resolution of inflammation might reassure the patient that the current therapy was effective.

Despite the more aggressive treatment in the ultrasound tight control group, inflammation assessed by ultrasound was significantly suppressed in both study arms, with most patients having no power Doppler activity in any joint after two years (appendix figure S1). A possible explanation may be that isolated subclinical inflammation in the absence of clinically detectable disease activity has minimal clinical importance, making direct visualisation of power Doppler activity unnecessary. We found a trend towards a difference in progression of joint damage, and we do not know whether a longer follow-up period would have shown a benefit of the ultrasound strategy. However, only a very subtle difference existed in the total modified Sharp score in the progression between the groups. In a study of patients with early rheumatoid arthritis who were followed over 10 years, a longitudinal association between total modified Sharp scores and functional outcome assessed by Health Assessment Questionnaire was found, and an increase of 10 units in the radiographic score was associated with a 0.03 unit increase (worsening) in Health 
Assessment Questionnaire score, which has a total range of 0-3 units. ${ }^{50}$ Thus, the observed difference of 0.45 modified Sharp score units over 24 months in our study is not clinically meaningful. The difference is present only in the erosion score and not in the joint space narrowing score, which has been found to be more strongly associated with irreversible loss of function than is erosive damage. ${ }^{51}$ The observed trend in the erosive score may be due to more frequent initiation of biologic drugs in the ultrasound tight control group, which is known to inhibit radiographic progression independently of disease activity. ${ }^{4}$

\section{Implications for policy makers}

New drugs commonly undergo health economic evaluations before they are funded through national healthcare systems or private medical insurance, whereas such evaluations are less strictly imposed for new imaging modalities and other medical techniques before implementation into clinical care. Although we did not aim to analyse cost effectiveness data, the lack of gain in benefits and the increased costs, time consumption, and use of biologic drugs associated with the ultrasound tight control regimen would yield negative cost-benefit ratios.

\section{Conclusions and future research}

The ARCTIC study highlights the importance of conducting randomised controlled trials to evaluate not only drugs but also new technologies or new treatment strategies. The implementation and systematic use of ultrasound in the follow-up of patients with early rheumatoid arthritis treated with an aggressive tight control strategy is not justified on basis of the results of the ARCTIC trial, and the result should be reflected in future recommendations and guidelines for managing patients with rheumatoid arthritis. Ultrasound may have an important role in the diagnosis of rheumatoid arthritis and in procedures such as intra-articular injections. Future studies should focus on the potential benefit of ultrasound in these areas, as well as the possible role of ultrasound in evaluating disease activity and tailoring treatment in patients with established rheumatoid arthritis.

\section{AUTHOR AFFILIATIONS}

'Department of Rheumatology, Diakonhjemmet Hospital, Box 23 Vinderen, 0319 Oslo, Norway

2Department of Rheumatology, Ålesund Hospital, Ålesund, Norway

3Department of Rheumatology, Haukeland University Hospital, Bergen, Norway

${ }^{4}$ Department of Rheumatology, Drammen Hospital, Drammen, Norway

${ }^{5}$ Department of Rheumatology, Martina Hansens Hospital AS, Sandvika, Norway

${ }^{6}$ Department of Rheumatology, St Olavs Hospital, Trondheim University Hospital, Trondheim, Norway

7Department of Rheumatology, Hospital Østfold HF Moss, Grålum, Norway

${ }^{8}$ Haugesund Rheumatism Hospital AS, Haugesund, Norway

${ }^{9}$ The Rheumatology Clinic Dovland/Bendvold, Kristiansand, Norway

${ }^{10}$ Department of Rheumatology, Sørlandet Hospital HF, Kristiansand, Norway

${ }^{11}$ Department of Rheumatology, University Hospital of North Norway, Tromsø, Norway
${ }^{12}$ Institute of Clinical Medicine, University of Troms $\varnothing$, Troms $\varnothing$, Norway ${ }^{13}$ Department of Rheumatology, Leiden University Medical Center, Leiden, Netherlands

We thank all the patients who participated in the study, as well as the investigators and medical staff at all participating centres for their contributions to the study. We also thank Ellen Moholt, Camilla Fongen, and Maria K Jonsson for their contributions to the data collection.

Contributors: EAH and ABA designed the study; recruited and enrolled participants; collected, analysed, and interpreted data; and wrote the report. ICO designed the study, analysed and interpreted data, and wrote the report. SL and LBN analysed and interpreted data and wrote the report. HBH designed the study, recruited participants, interpreted data, and reviewed the manuscript. TU designed the study, recruited and enrolled participants, interpreted data, and reviewed the manuscript. HF, TMM, ÅSL, HH, ER, CH, HS, ANB, IJWH, and GB recruited and enrolled patients, interpreted data, and reviewed the manuscript. DvdH and TKK designed the study, interpreted data, and reviewed the manuscript. All authors have approved the final draft and vouch for the accuracy and completeness of the data and analyses. $\mathrm{EAH}$ is the guarantor.

Funding: This trial was supported by the Norwegian Research Council, Norwegian South-Eastern Health Region, Norwegian Women's Public Health Association, Norwegian Rheumatism Association, investigator initiated research grants from AbbVie, UCB Pharma, Pfizer Inc, MSD Norway, and Roche Norway. Siemens Healthcare and GE Healthcare provided technical support regarding standardisation of ultrasound equipment. The funders of the study had no role in study design, data collection, data analysis, data interpretation, or writing of the report. The corresponding author had full access to all the data in the study and had final responsibility for the decision to submit for publication.

Competing interests: All authors have completed the ICMJE uniform disclosure form at www.icmje.org/coi_disclosure.pdf (available on request from the corresponding author) and declare: EAH has received research funding from Pfizer, UCB, Roche, MSD, and AbbVie for the submitted work, honorariums as a speaker from Pfizer, UCB, Roche, and AbbVie, and honorariums for development of educational material from Pfizer and has sat on advisory boards for Pfizer; ABA has sat on advisory boards for UCB, AbbVie, and Pfizer and received honorariums for development of educational material for UCB; $\mathrm{HBH}$ has received honorariums as a speaker from AbbVie, Bristol-Myers Squibb, Roche, UCB Pharma, and Pfizer; HH has sat on advisory boards for UCB and AbbVie; GB has received honorariums as a speaker from AbbVie and has sat on advisory boards for Pfizer; DvdH has received consultancy honorariums from AbbVie, Amgen, Astellas, AstraZeneca, Bristol-Myers Squibb, Celgene, Daiichi, Eli Lilly, Galapagos, Merck, Novartis, Pfizer, Roche, Sanofi Aventis, Janssen, and UCB and is owner of Imaging Rheumatology; TKK has received consultancy honorariums from AbbVie, Bristol-Myers Squibb, Celltrion, Epirus, Hospira, Merck-Serono, MSD, Orion Pharma, Pfizer, and UCB; no other relationships or activities that could appear to have influenced the submitted work.

Ethical approval: The study protocol and consent documents were approved by an independent ethics committee (the Regional Committee for Medical and Health Research Ethics South-East; reference number 2010/744) and appropriate institutional review boards.

Data sharing: The authors commit to making the relevant anonymised patient level data available on reasonable request.

Transparency: The lead author affirms that the manuscript is an honest, accurate, and transparent account of the study being reported; that no important aspects of the study have been omitted; and that any discrepancies from the study as planned (and, if relevant, registered) have been explained.

Preliminary reports: Preliminary reports of the ARCTIC trial have been presented at the Annual Meeting of the American College of Rheumatology in San Francisco (10 November 2015) and the European League Against Rheumatism (EULAR) Annual Congress of Rheumatology in London (9 June 2016).

This is an Open Access article distributed in accordance with the Creative Commons Attribution Non Commercial (CC BY-NC 3.0) license, which permits others to distribute, remix, adapt, build upon this work non-commercially, and license their derivative works on different terms, provided the original work is properly cited and the use is non-commercial. See: http://creativecommons.org/licenses/by-nc/3.0/.

Grigor C, Capell H, Stirling A, et al. Effect of a treatment strategy of tight control for rheumatoid arthritis (the TICORA study): a single-blind randomised controlled trial. Lancet 2004;364:263-9. doi:10.1016/S0140-6736(04)16676-2. 
2 Verstappen SM, Jacobs JW, van der Veen MJ, et al. Utrecht Rheumatoid Arthritis Cohort study group. Intensive treatment with methotrexate in early rheumatoid arthritis: aiming for remission. Computer Assisted Management in Early Rheumatoid Arthritis (CAMERA, an open-label strategy trial). Ann Rheum Dis 2007:66:1443-9. doi:10.1136/ard.2007.071092.

3 Smolen JS, Aletaha D, Bijlsma JW, et al. T2T Expert Committee. Treating rheumatoid arthritis to target: recommendations of an international task force. Ann Rheum Dis 2010;69:631-7. doi:10.1136/ard.2009.123919.

4 Klareskog L, Catrina Al, Paget S. Rheumatoid arthritis. Lancet 2009;373:659-72. doi:10.1016/S0140-6736(09)60008-8.

5 Breedveld FC, Weisman MH, Kavanaugh AF, et al. The PREMIER study A multicenter, randomized, double-blind clinical trial of combination therapy with adalimumab plus methotrexate versus methotrexate alone or adalimumab alone in patients with early, aggressive rheumatoid arthritis who had not had previous methotrexate treatment. Arthritis Rheum 2006:54:26-37. doi:10.1002/art.21519.

6 Genovese MC, Bathon JM, Martin RW, et al. Etanercept versus methotrexate in patients with early rheumatoid arthritis: two-year radiographic and clinical outcomes. Arthritis Rheum 2002;46:144350. doi:10.1002/art.10308

7 Weinblatt ME, Keystone EC, Furst DE, et al. Adalimumab, a fully human anti-tumor necrosis factor alpha monoclonal antibody, for the treatment of rheumatoid arthritis in patients taking concomitant methotrexate: the ARMADA trial. Arthritis Rheum 2003;48:35-45. doi:10.1002/art.10697

8 St Clair EW, van der Heijde DM, Smolen IS, et al. Active-Controlled Study of Patients Receiving Infliximab for the Treatment of Rheumatoid Arthritis of Early Onset Study Group. Combination of infliximab and methotrexate therapy for early rheumatoid arthritis: a randomized, controlled trial. Arthritis Rheum 2004;50:3432-43. doi:10.1002/art.20568.

9 Aga AB, Lie E, Uhlig T, et al. Time trends in disease activity, response and remission rates in rheumatoid arthritis during the past decade: results from the NOR-DMARD study 2000-2010. Ann Rheum Dis 2015;74:381-8. doi:10.1136/annrheumdis-2013-204020.

10 Smolen JS, Breedveld FC, Burmester GR, et al. Treating rheumatoid arthritis to target: 2014 update of the recommendations of an international task force. Ann Rheum Dis 2016;75:3-15. doi:10.1136/ annrheumdis-2015-207524.

11 Smolen JS, Landewé R, Breedveld FC, et al. EULAR recommendations for the management of rheumatoid arthritis with synthetic and biological disease-modifying antirheumatic drugs: 2013 update. Ann Rheum Dis 2014:73:492-509. doi:10.1136/annrheumdis-2013-204573.

12 Stoffer MA, Schoels MM, Smolen JS, et al. Evidence for treating rheumatoid arthritis to target: results of a systematic literature search update. Ann Rheum Dis 2016;75:16-22. doi:10.1136/ annrheumdis-2015-207526.

13 Singh JA, Saag KG, Bridges SL Jr, et al. American College of Rheumatology. 2015 American College of Rheumatology Guideline for the Treatment of Rheumatoid Arthritis. Arthritis Care Res (Hoboken) 2016;68:1-25. doi:10.1002/acr.22783.

14 Lillegraven S, Prince FH, Shadick NA, et al. Remission and radiographic outcome in rheumatoid arthritis: application of the 2011 ACR/EULAR remission criteria in an observational cohort. Ann Rheum Dis 2012;71:681-6. doi:10.1136/ard.2011.154625.

15 Felson DT, Smolen JS, Wells G, et al. American College of Rheumatology/European League against Rheumatism provisional definition of remission in rheumatoid arthritis for clinical trials. Ann Rheum Dis 2011;70:404-13. doi:10.1136/ard.2011.149765.

16 Szkudlarek M, Wakefield RJ, Backhaus M, Terslev L. The discriminatory capacity of ultrasound in rheumatoid arthritis: active vs inactive, early vs advanced, and more. Rheumatology (Oxford) 2012;51(Suppl 7):vii6-9. doi:10.1093/rheumatology/kes334

17 Dougados M, Jousse-Joulin S, Mistretta F, et al. Evaluation of several ultrasonography scoring systems for synovitis and comparison to clinical examination: results from a prospective multicentre study of rheumatoid arthritis. Ann Rheum Dis 2010;69:828-33. doi:10.1136/ ard.2009.115493.

18 Mandl P, Naredo E, Wakefield RJ, Conaghan PG, D’Agostino MA. OMERACT Ultrasound Task Force. A systematic literature review analysis of ultrasound joint count and scoring systems to assess synovitis in rheumatoid arthritis according to the OMERACT filter I Rheumatol 2011;38:2055-62. doi:10.3899/jrheum.110424.

19 Colebatch AN, Edwards Cl, Østergaard M, et al. EULAR recommendations for the use of imaging of the joints in the clinical management of rheumatoid arthritis. Ann Rheum Dis 2013;72:804-14. doi:10.1136/annrheumdis-2012-203158

20 Matsos M, Harish S, Zia P, et al. Ultrasound of the hands and feet for rheumatological disorders: influence on clinical diagnostic confidence and patient management. Skeletal Radiol 2009;38:1049-54. doi:10.1007/s00256-009-0738-2.

21 Filer A, de Pablo P, Allen G, et al. Utility of ultrasound joint counts in the prediction of rheumatoid arthritis in patients with very early synovitis. Ann Rheum Dis 2011;70:500-7. doi:10.1136/ ard.2010.131573.
22 Agrawal S, Bhagat SS, Dasgupta B. Improvement in diagnosis and management of musculoskeletal conditions with one-stop clinic-based ultrasonography. Mod Rheumatol 2009;19:53-6. doi:10.3109/s10165-008-0122-4.

23 Sibbitt WL Jr, Peisajovich A, Michael AA, et al. Does sonographic needle guidance affect the clinical outcome of intraarticular injections? J Rheumatol 2009;36:1892-902. doi:10.3899/ jrheum.090013.

24 Hammer HB, Terslev L. Role of ultrasound in managing rheumatoid arthritis. Curr Rheumatol Rep 2012:14:438-44. doi:10.1007/ s11926-012-0266-2

25 Saleem B, Brown AK, Quinn M, et al. Can flare be predicted in DMARD treated RA patients in remission, and is it important? A cohort study. Ann Rheum Dis 2012;71:1316-21. doi:10.1136/ annrheumdis-2011-200548.

26 Brown AK, Conaghan PG, Karim Z, et al. An explanation for the apparent dissociation between clinical remission and continued structural deterioration in rheumatoid arthritis. Arthritis Rheum 2008;58:2958-67. doi:10.1002/art.23945.

27 Brown AK, Quinn MA, Karim Z, et al. Presence of significant synovitis in rheumatoid arthritis patients with disease-modifying antirheumatic drug-induced clinical remission: evidence from an imaging study may explain structural progression. Arthritis Rheum 2006;54:3761-73. doi:10.1002/art 22190.

28 Peluso G, Michelutti A, Bosello S, Gremese E, Tolusso B, Ferraccioli G. Clinical and ultrasonographic remission determines different chances of relapse in early and long standing rheumatoid arthritis. Ann Rheum Dis 2011;70:172-5. doi:10.1136/ard.2010.129924

29 Scirè CA, Montecucco C, Codullo V, Epis O, Todoerti M, Caporali R. Ultrasonographic evaluation of joint involvement in early rheumatoid arthritis in clinical remission: power Doppler signal predicts short-term relapse. Rheumatology (Oxford) 2009;48:1092-7. doi:10.1093/rheumatology/kep171.

30 Nguyen H, Ruyssen-Witrand A, Gandjbakhch F, Constantin A, Foltz V, Cantagrel A. Prevalence of ultrasound-detected residual synovitis and risk of relapse and structural progression in rheumatoid arthritis patients in clinical remission: a systematic review and meta-analysis. Rheumatology (Oxford) 2014;53:2110-8. doi:10.1093/rheumatology/ keu217.

31 Haavardsholm EA, Lie E, Lillegraven S. Should modern imaging be part of remission criteria in rheumatoid arthritis? Best Pract Res Clin Rheumatol 2012;26:767-85. doi:10.1016/j.berh.2012. 10.004.

32 Wakefield RJ, D’Agostino MA, Naredo E, et al. After treat-to-target: can a targeted ultrasound initiative improve RA outcomes? Postgrad Med / 2012;88:482-6. doi:10.1136/postgradmedj-2011201048rep.

33 Østergaard M, Møller-Bisgaard S. Rheumatoid arthritis: Is imaging needed to define remission in rheumatoid arthritis? Nat Rev Rheumatol 2014;10:326-8. doi:10.1038/nrrheum.2014.63.

34 van der Heijde D. Remission by imaging in rheumatoid arthritis: should this be the ultimate goal? Ann Rheum Dis 2012;71(Suppl 2):i89-92. doi:10.1136/annrheumdis-2011-200797.

35 Møller-Bisgaard S, Hørslev-Petersen K, Ejbjerg BJ, et al. Impact of a magnetic resonance imaging-guided treat-to-target strategy on disease activity and progression in patients with rheumatoid arthritis (the IMAGINE-RA trial): study protocol for a randomized controlled trial. Trials 2015;16:178. doi:10.1186/s13063-0150693-2.

36 Aletaha D, Neogi T, Silman AJ, et al. 2010 rheumatoid arthritis classification criteria: an American College of Rheumatology/ European League Against Rheumatism collaborative initiative. Ann Rheum Dis 2010;69:1580-8. doi:10.1136/ard.2010.138461.

37 Hammer HB, Bolton-King P, Bakkeheim V, et al. Examination of intra and interrater reliability with a new ultrasonographic reference atlas for scoring of synovitis in patients with rheumatoid arthritis. Ann Rheum Dis 2011;70:1995-8. doi:10.1136/ard.2011. 152926.

38 Torp-Pedersen ST, Terslev L. Settings and artefacts relevant in colour/ power Doppler ultrasound in rheumatology. Ann Rheum Dis 2008;67:143-9. doi:10.1136/ard.2007.078451.

39 van Riel PL, van Gestet AM, Scott DL. EULAR handbook of clinical assessments in rheumatoid arthritis: on behalf of the EULAR Standing Committee for International Clinical Studies Including Therapeutic Trials-ESCISIT. Van Zuiden, 2000

40 van der Heijde DM, van 't Hof MA, van Riel PL, et al. Judging disease activity in clinical practice in rheumatoid arthritis: first step in the development of a disease activity score. Ann Rheum Dis 1990;49:91620. doi:10.1136/ard.49.11.916.

41 van Gestel AM, Prevoo ML, van 't Hof MA, van Rijswijk MH, van de Putte LB, van Riel PL. Development and validation of the European League Against Rheumatism response criteria for rheumatoid arthritis. Comparison with the preliminary American College of Rheumatology and the World Health Organization/International League Against Rheumatism Criteria. Arthritis Rheum 1996;39:34-40. doi:10.1002/art.1780390105 
42 Bruynesteyn K, Van Der Heijde D, Boers M, et al. Detecting radiological changes in rheumatoid arthritis that are considered important by clinical experts: influence of reading with or without known sequence. J Rheumatol 2002;29:2306-12.

43 Hetland ML, Stengaard-Pedersen K, Junker P, et al. CIMESTRA study group. Aggressive combination therapy with intra-articular glucocorticoid injections and conventional disease-modifying anti-rheumatic drugs in early rheumatoid arthritis: second-year clinical and radiographic results from the CIMESTRA study. Ann Rheum Dis 2008:67:815-22. doi:10.1136/ard.2007.076307.

44 Hørslev-Petersen K, Hetland ML, Junker P, et al. OPERA Study-Group. Adalimumab added to a treat-to-target strategy with methotrexate and intra-articular triamcinolone in early rheumatoid arthritis increased remission rates, function and quality of life. The OPERA Study: an investigator-initiated, randomised, double-blind, parallel-group, placebo-controlled trial. Ann Rheum Dis 2014;73:654 61. doi:10.1136/annrheumdis-2012-202735.

45 Detert J, Bastian H, Listing J, et al. Induction therapy with adalimumab plus methotrexate for 24 weeks followed by methotrexate monotherapy up to week 48 versus methotrexate therapy alone for DMARD-naive patients with early rheumatoid arthritis: HIT HARD, an investigator-initiated study. Ann Rheum Dis 2013;72:844-50. doi:10.1136/annrheumdis-2012-201612.

46 O'Dell JR, Mikuls TR, Taylor TH, et al. CSP 551 RACAT Investigators. Therapies for active rheumatoid arthritis after methotrexate failure. N Engl J Med 2013;369:307-18. doi:10.1056/NEJMoa1303006.
47 Dale J, Stirling A, Zhang R, et al. Targeting ultrasound remission in early rheumatoid arthritis: the results of the TaSER study, a randomised clinical trial. Ann Rheum Dis 2016;75:1043-50. doi:10.1136/annrheumdis-2015-208941.

48 Gärtner M, Alasti F, Supp G, Mandl P, Smolen JS, Aletaha D. Persistence of subclinical sonographic joint activity in rheumatoid arthritis in sustained clinical remission. Ann Rheum Dis 2015;74:2050-3. doi:10.1136/annrheumdis-2014-207212.

49 Markusse IM, Dirven L, Han KH, et al. Evaluating Adherence to a Treat-to-Target Protocol in Recent-Onset Rheumatoid Arthritis: Reasons for Compliance and Hesitation. Arthritis Care Res (Hoboken) 2016;68:446-53. doi:10.1002/acr.22681.

50 Ødegård S, Landewé R, van der Heijde D, Kvien TK, Mowinckel P, Uhlig T. Association of early radiographic damage with impaired physical function in rheumatoid arthritis: a ten-year, longitudinal observational study in 238 patients. Arthritis Rheum 2006;54:68-75. doi:10.1002/ art.21548.

51 Aletaha D, Funovits J, Smolen JS. Physical disability in rheumatoid arthritis is associated with cartilage damage rather than bone destruction. Ann Rheum Dis 2011;70:733-9. doi:10.1136/ ard.2010.138693.

(c) BMJ Publishing Group Ltd 2016

\section{Appendix}

